\title{
Hubungan Kepatuhan Tim Bedah dalam Penerapan Surgery Safety Checklist (Ssc) Dengan Infeksi Luka Operasi dan Lama Rawat Inap Pada Pasien Seksio Sesarea di Rumah Sakit Umum Daerah Kabupaten Barru
}

\author{
Amiruddin ${ }^{1}$, Ova Emilia², Shinta Prawitasari ${ }^{3}$, Leo Prawirodihardjo ${ }^{4}$ \\ ${ }^{1}$ RSUD Kabupaten Barru \\ ${ }^{2,3}$ Departemen Obstetri dan Ginekologi, Fakultas Kedokteran, Kesehatan Masyarakat dan Keperawatan, UGM \\ ${ }^{4}$ RSKD St Fatimah, Kota Makassar \\ Korespondensi: amiruddinsaini@gmail.com
}

Submisi:15 Oktober 2018; Revisi: 19 Desember 2018; Penerimaan: 20 Desember 2018

\begin{abstract}
Background: Surgical Patient Safety is essential to be carried out in operating theatre to prevent mortality and surgical complication. Patient safety is the basic principal in medical care and a major component of medical care management in hospital (WHO, 2009).

Objective: To investigate association between SSC implementation among surgical team, surgical site infection and duration of hospital stay after C. Section.

Method: This is an analytical cross sectional study. Population of this study was women who underwent cesarean section with live birth in Barru general hospital during 1 December 2016-30 April 2017. One hundred and thirty seven samples met inclusion and exclusion criteria. Data was obtained from medical records. Maternal outcome were duration of hospital stay, surgical site infection, and maternal mortality. Furthermore this study also assesed knowledge and compliance of surgical team in implementation of SSC. The result of this study was analysed with computer statisctics analysis program.

Result and Discussion: One-hundred thirty seven patients met study criteria. Compliance of surgery team in SSC was $64 \%$,. SSC was not implemented precisely in $36 \%$ patients (49 patients). There is no significant association between surgical team compliance with surgical site infection in cesarean section patients $(\mathbf{p}=\mathbf{0 . 0 7 8})$. A significant association was found between surgical team compliance with duration of hospital stay $(\mathbf{p}=\mathbf{0 . 0 0 6})$.

Conclusion: The surgical team compliance in implementation of SSC was not yet optimal. An intensive socialization is needed to improve compliance of team in order that SSC implementation run promptly. This was part of efforts to reduce post operative complication and shorten hospital stay.
\end{abstract}

Keywords: SSC; cesarean section; complianc; infection; duration of hospital stay

\begin{abstract}
ABSTRAK
Latar Belakang: Surgical Patient Safety sangat penting dilakukan di kamar operasi untuk mencegah kematian dan komplikasi akibat pembedahan. Keselamatan pasien merupakan prinsip dasar dalam pemberian pelayanan dan merupakan komponen sangat penting dalam manajemen pelayanan kesehatan di rumah sakit (WHO,2009).

Tujuan: Untuk mengetahui adanya hubungan antara kepatuhan tim bedah dalam penerapan SSC dengan infeksi luka operasi dan lamanya hari rawat inap pasien seksio sesarea

Metode: Analitik cross sectional. Populasi penelitian adalah ibu yang menjalani seksio sesarea dengan bayi hidup di RSUD Barru periode 1 Desember 2016-30 April 2017 . Penelitian dilakukan di RSUD Barru. Jumlah sampel adalah 137 pasien yang memenuhi kriteria inklusi dan eksklusi.Data diperoleh melalui rekam medik.Luaran maternal yang dinilai adalah lama perawatan, infeksi luka operasi, dan kematian ibu. Selain itu penelitian ini juga menilai pengetahuan dan kepatuhan tim bedah terhadap penerapan SSC . Hasil dianalisis dengan statistika menggunakan komputer.

Hasil dan Pembahasan: Terdapat 137 pasien yang memenuhi kriteria. Kepatuhan tim bedah dalam penerapan SSC hanya 64\% dan ada 36\% (49 pasien) tidak dilakukan sepenuhnya (tidak patuh). Tidak terdapat hubungan bermakna antara kepatuhan tim bedah dengan tidak terjadinya infeksi luka operasi pada pasien seksio sesarea $(\mathbf{p}=\mathbf{0 , 0 7 8})$, tetapi ada hubungan yang signifikan antara kepatuhan tim bedah dengan lamanya hari rawat inap $(\mathbf{p}=0,006)$.

Kesimpulan: Kepatuhan tim bedah dalam penerapan SSC masih belum optimal, sehingga masih diperlukan adanya sosialisasi yang lebih intensif untuk meningkatkan kepatuhan tim agar penerapan SSC dapat berjalan dengan baik dan benar sebagai bagian dari upaya dalam mengurangi komplikasi pasca operasi dan mempersingkat hari rawat inap
\end{abstract}

Kata kunci: SSC; seksio sesarea; kepatuhan; infeksi; hari rawat inap 


\section{PENDAHULUAN}

Pembedahan merupakan salah satu tindakan medis yang penting dalam pelayanan kesehatan. Tindakan pembedahan merupakan salah satu tindakan medis yang bertujuan untuk menyelamatkan nyawa, mencegah kecacatan dan komplikasi. Namun demikian, pembedahan yang dilakukan juga dapat menimbulkan komplikasi yang dapat membahayakan nyawa. ${ }^{1}$

Jumlah tindakan pembedahan di dunia sangat besar, hasil penelitian di 56 negara pada tahun 2004 diperkirakan jumlah tindakan pembedahan sekitar 234 juta per tahun, hampir dua kali lipat melebihi angka kelahiran per tahun. Studi pada negara-negara industri, angka komplikasi tindakan pembedahan diperkirakan 3-16\% dengan kematian 0,4-0,8\%. Delapan studi retrospektif tentang kejadian tidak diharapkan (KTD) di rumah sakit, insidens yang terjadi di rumah sakit sebesar 9,2\% dan hampir separuhnya dapat dicegah (43,5\%). Sebagian besar KTD terjadi saat pasien di rumah sakit $(80,8 \%)$ dan pada tindakan pembedahan $58,4 \%$ dari semua KTD yang ada di rumah sakit. Dari KTD di rumah sakit tersebut, mayoritas $(41 \%)$ terjadi di kamar bedah. ${ }^{2}$ Komplikasi infeksi luka operasi menjadi komplikasi umum kedua setelah infeksi saluran kemih, sehingga menimbulkan biaya tambahan untuk rawat inap. Berdasarkan penelitian di rumah sakit pada 715 pasien di Inggris ditemukan 80 pasien terkena infeksi luka operasi pasca seksio sesarea. ${ }^{3}$

WHO memprediksi bahwa dampak dari intervensi bedah pada sistem kesehatan masyarakat akan terus tumbuh. Untuk alasan ini, WHO telah melakukan inisiatif untuk upaya keselamatan bedah. Sebuah badan untuk keselamatan pasien mulai bekerja pada Januari 2007 dan WHO mengidentifikasi tiga fase operasi yaitu sebelum induksi anestesi (sign in), sebelum sayatan kulit (time out) dan sebelum pasien meninggalkan ruang operasi (sign out). ${ }^{4}$

Pada tahun 2008 WHO mempublikasikan pedoman yang berisi langkah- langkah praktis untuk memastikan keselamatan pasien dalam perawatan operasi (surgical safety checklist guidelines). Pedoman tersebut berisikan tiga elemen utama yaitu : ceklis tindakan sebelum menginjeksikan anastesi, ceklis tindakan sebelum insisi dan ceklis tindakan sebelum pasien meninggalkan kamar operasi. Uji coba terhadap ceklis ini telah dilakukan oleh Haynes
, et al. pada tahun 2007-2008 yang menunjukkan hasil penggunaan SSC di ruang operasi pada delapan rumah sakit yang berbeda berdampak positif pada penurunan angka komplikasi dari $11 \%$ menjadi $7 \%$ dan penurunan angka kematian pasca tindakan bedah dari $1,5 \%$ menjadi $0,8 \%{ }^{1}$

SSC diterapkan di bagian bedah dan anestesi untuk meningkatkan kualitas dan menurunkan kematian serta komplikasi akibat pembedahan. Tindakan pembedahan memerlukan persamaan persepsi antara ahli bedah, anestesi dan perawat. ${ }^{5}$ SSC berisi 24 item yang harus dilakukan dalam tiga tahap. ${ }^{6}$

Masih tingginya komplikasi pasca operasi seksio sesarea khususnya angka infeksi pasca seksio sesarea di RSUD Barru, maka dirasa perlu untuk menerapkan secara benar SSC.

Data yang diperoleh dari rekam medik pasien yang menjalani seksio sesarea dari desember 2015 hingga April 2016 di RSUD Kab.Barru didapatkan angka infeksi pasca seksio sesarea dan lamanya rawat inap pasien hingga $>4$ hari masih cukup tinggi yaitu $21,8 \%$ dan $60,1 \%$.

Sebenarnya di rentang waktu tersebut sudah diterapkan ketentuan penggunaan SSC di RSUD Barru, namun karena sosialisasi dan penerapannya yang belum maksimal sehingga manfaatnya terhadap pasien belum terlihat. Diharapkan dengan penelitian ini akan memberi masukan ke RS dan menjadi bahan koreksi terhadap penerapan SSC yang belum berjalan dengan baik dan benar.

\section{METODE}

Penelitian menggunakan metode Analitik cross sectional, dilakukan di RSUD Barru. Jumlah sampel adalah 137 pasien yang memenuhi kriteria inklusi dan eksklusi.

Kriteria inklusi pada penelitian ini adalah sebagai berikut: a) Seluruh perempuan yang masuk di IRD dan poli kebidanan RSUD Barru yang memerlukan tindakan seksio sesarea. B) Semua perempuan yang masih memiliki harapan hidup saat diupayakan tindakan operasi .c) Perempuan yang akan dilakukan seksio sesarea tanpa adanya kontraindikasi operasi, contoh: kelainan darah, penyakit gagal ginjal dan jantung, alergi obat anestesi. d) Bersedia untuk dilakukan operasi. 
Sedangkan Kriteria eksklusi pada penelitian ini adalah sebagai berikut: a) Wanita hamil dengan kematian janin dalam rahim (KJDR) yang memerlukan tindakan operasi Seksio sesaria, misalnya: plasenta previa totalis. b) Pasien dengan penyakit sistemik sehingga membutuhkan perawatan intensif sebelum dilakukan operasi.

Penelitian menggunakan alat pengumpulan data berupa lembar data yang diambil dari status pasien (Rekam Medik), lembar surgery safety Checklist yang berisi beberapa item yang harus dilakukan tim kamar operasi dan merupakan bagian yang sudah terintegrasi di dalam rekam medik pasien juga melalui wawancara. Kuesioner yang digunakan ada 2 yaitu kuesioner tim bedah berisi 25 pertanyaan tentang SSC untuk menilai tim bedah dan kuesioner ibu yang berisi hasil wawancara dan anamnesis serta hasil pemeriksaan tambahan lainnya. Selain itu juga lembar penilaian ceklis berisi item ceklis pada fase Sign in, Time Out, dan Sign Out untuk menilai kepatuhan tim bedah.

\section{HASIL DAN PEMBAHASAN}

\section{Karakteristik responden dan luaran maternal}

Hasil ini dapat dilihat pada tabel 1 yang juga membandingkan data pada tahun sebelumnya yang diambil dari rekam medik RS (periode desember 2015-April 2016)

Tabel 1. Karakteristik responden di RSUD Barru periode Desember 2016 - April 2017

\begin{tabular}{|c|c|c|c|c|}
\hline \multirow{2}{*}{ Karakteristik } & \multicolumn{2}{|c|}{ Des 2015 - Apr 2016} & \multicolumn{2}{|c|}{ Des 2016 - Apr 2017} \\
\hline & $\mathbf{n}$ & $\%$ & $\mathbf{n}$ & $\%$ \\
\hline \multicolumn{5}{|l|}{ Umur } \\
\hline$<20$ tahun & 5 & 3,8 & 4 & 2,9 \\
\hline 20- 35 tahun & 81 & 60,9 & 105 & 76,6 \\
\hline$>35$ tahun & 47 & 35,3 & 28 & 20,5 \\
\hline \multicolumn{5}{|l|}{ Paritas } \\
\hline 0 & 54 & 40,6 & 60 & 43,8 \\
\hline $1-3$ & 67 & 50,4 & 67 & 48,9 \\
\hline$>3$ & 12 & 9,0 & 10 & 7,3 \\
\hline \multicolumn{5}{|l|}{ Diagnosis penyakit } \\
\hline KPD & 26 & 19,6 & 39 & 28,5 \\
\hline Postterm dan gagal induksi & 18 & 13,5 & 8 & 5,8 \\
\hline Plasenta previa & 6 & 4,5 & 9 & 6,6 \\
\hline CPD, Malposisi & 24 & 18,1 & 27 & 19,7 \\
\hline Riwayat sesar & 12 & 9,0 & 18 & 13,1 \\
\hline Partus lama & 23 & 17,3 & 13 & 9,5 \\
\hline Preeklamsia & 16 & 12,0 & 11 & 8,0 \\
\hline Gemelli & 2 & 1,5 & 2 & 1,5 \\
\hline Gawat janin & 3 & 2,3 & 5 & 3,6 \\
\hline Riwayat obstetri jelek & 1 & 0,8 & 2 & 1,5 \\
\hline Primigravia tua & 0 & 0 & 1 & 0,7 \\
\hline Anak besar & 2 & 1,5 & 2 & 1,5 \\
\hline \multicolumn{5}{|l|}{ Infeksi luka operasi } \\
\hline Ya & 29 & 21,8 & 14 & 10,2 \\
\hline Tidak & 104 & 78,2 & 123 & 89,8 \\
\hline \multicolumn{5}{|l|}{ Lama rawat inap } \\
\hline$>4$ hari & 80 & 60,1 & 57 & 41,6 \\
\hline$\leq 4$ hari & 53 & 39,9 & 80 & 58.4 \\
\hline \multicolumn{5}{|l|}{ Kematian maternal } \\
\hline Tidak & 133 & 100 & 137 & 100 \\
\hline $\mathrm{Ya}$ & 0 & 0 & 0 & 0 \\
\hline Total & 133 & 0 & 137 & 100 \\
\hline
\end{tabular}


Pada tabel 1 terlihat bahwa dari 137 pasien yang masuk dalam penelitian ini subyek terbanyak pada kelompok umur 20-35 tahun (76,6\%), paritas 1-3 (48,9\%) dan diagnosis ketuban pecah dini $(28,5 \%)$. LO ditemukan pada 14 pasien $(10,2 \%)$ menurun dibanding tahun sebelumnya yaitu 29 pasien $(21,8 \%)$. Lama perawatan $>4$ hari ditemukan pada 57 pasien $(41,6 \%)$, menurun dibanding tahun sebelumnya yaitu 80 pasien $(60,1 \%)$.

\section{Gambaran diagnosis dalam kaitannya dengan infeksi luka operasi dan lama rawat inap}

Tabel 2. Gambaran diagnosis hubungan ILO dengan lama rawat inap pasien pasca seksio sesarea di RSUD Barru

\begin{tabular}{lcccccccc}
\hline \multirow{2}{*}{ Diagnosis } & \multicolumn{2}{c}{ Infeksi } & \multicolumn{2}{c}{ Tidak Infeksi } & \multicolumn{2}{c}{$>$ 4 hari } & \multicolumn{2}{c}{$\leq$ 4hari } \\
\cline { 2 - 9 } & $\mathbf{n}$ & $\mathbf{\%}$ & $\mathbf{n}$ & $\mathbf{\%}$ & $\mathbf{n}$ & $\mathbf{\%}$ & $\mathbf{n}$ & $\%$ \\
\hline KPD & 5 & 35,7 & 34 & 27,6 & 15 & 26,3 & 24 & 30,0 \\
Post Term, Gagal Induksi & 0 & 0 & 8 & 6,5 & 2 & 3,5 & 6 & 7,4 \\
Plasenta Previa & 2 & 14,3 & 7 & 5,7 & 5 & 8,8 & 4 & 5,0 \\
Malpresentasi, CPD & 4 & 28,6 & 23 & 18,7 & 12 & 21,1 & 15 & 18,7 \\
Riwayat Seksio Sesarea & 0 & 0 & 18 & 14,6 & 8 & 14,0 & 10 & 12,5 \\
Partus Lama & 3 & 21,4 & 10 & 8.1 & 3 & 5,3 & 10 & 12,5 \\
Preeklamsia, Eklamsia, HDK & 0 & 0 & 11 & 8.9 & 6 & 10,5 & 5 & 6,3 \\
Gemelli & 0 & 0 & 2 & 1,7 & 0 & 0 & 2 & 2,5 \\
Gawat Janin & 0 & 0 & 5 & 4,1 & 2 & 3,5 & 3 & 3,8 \\
Riwayat Obstetri Jelek & 0 & 0 & 2 & 1,7 & 1 & 1,8 & 1 & 1,3 \\
Primigravida Tua & 0 & 0 & 1 & 0,8 & 1 & 1,8 & 0 & 0 \\
Anak besar & 0 & 0 & 2 & 1,7 & 2 & 3,5 & 0 & 0 \\
Total & 14 & 100 & 123 & 100 & 57 & 100 & 80 & 100 \\
\hline
\end{tabular}

Tabel 2 menunjukkan bahwa KPD menjadi diagnosis terbanyak penyebab infeksi yaitu 5 pasien $(35,7 \%)$, kemudian malpsosisi dan CPD yaitu 4 pasien (28,6\%).

Lama hari rawat $>4$ hari juga terbanyak pada KPD yaitu 15 pasien (26,3\%) kemudian malposisi dan CPD yaitu 12 pasien $(21,1 \%)$.

\section{Gambaran pengetahuan rata-rata tim bedah terhadap SSC}

Tabel 3 memberikan gambaran pengetahuan rata-rata tim bedah yang terdiri dari 2 dokter obgin, 1 dokter anestesi, 3 perawat anestesi, dan 19 petugas OK setelah memberikan jawaban terhadap 25 pertanyaan dari kuesioner tentang SSC.

Tabel 3. Pengetahuan rata-rata tim bedah berdasarkan profesi/tugas masing-masing

\begin{tabular}{|l|c|c|c|l|}
\hline \multicolumn{1}{|c|}{ Tim Bedah } & Akumulasi Nilai & Jumlah personil & Rata-rata & \multicolumn{1}{|c|}{ Interpretasi } \\
\hline Dokter Obgin & 152 & 2 & 76 & Sangat baik \\
\hline Dokter Anestesi & 76 & 1 & 76 & Sangat baik \\
\hline Penata Anestesi & 188 & 3 & 62,7 & Cukup \\
\hline Perawat OK & 912 & 19 & 48 & Kurang \\
\hline Total & 1328 & 25 & 53,1 & Cukup \\
\hline
\end{tabular}


Dari hasil kuesioner ini menunjukkan bahwa pengetahuan dokter ahli terhadap SSC sudah sangat baik (76\%), perawat anestesi cukup $(62,7 \%)$, sedang perawat OK masih kurang $48 \%$ ( $<50 \%)$.

\section{Distribusi frekwensi kepatuhan tim bedah dalam melaksanakan SSC pada fase sign in, time out dan sign out}

Tabel 4, tabel 5, dan tabel 6 memperlihatkan bagian-bagian (item) dari SSC yang tidak dipatuhi oleh tim bedah. Tabel 4 memberikan gambaran pada fase sign in, tabel 5 pada fase time out, dan tabel 6 pada fase sign out. Penilaian kepatuhan ini dilakukan melalui kuesioner ceklis fase sign in, time out, dan sign out oleh dua orang secara bergantian yang dipercayakan oleh peneliti. Data kuesioner penilaian dikumpulkan dan dilihat frekwensi ketidakpatuhan petugas pada tiap bagian dari fase SSC.

Dari 137 pasien yang menjalani seksio sesarea terdapat 49 pasien $(35,7 \%)$ yang dikategorikan tidak patuh karena ada item yang tidak dilakukan, sedang 88 pasien $(64,3 \%)$ lainnya bisa dilakukan sepenuhnya tanpa ada item yang terlewatkan.

Hasil ini diharapkan bisa bermanfaat sebagai bahan audit RS terhadap kepatuhan petugas terhadap penerapan SSC.

Adapun hasil yang didapatkan adalah sebagai berikut :

Tabel 4 . Distribusi frekuensi kepatuhan tim bedah yang melaksanakan surgical safety checklist Fase sign in pada operasi seksio sesarea di RSUD Kab. Barru

\begin{tabular}{|c|c|c|c|c|c|c|c|}
\hline \multirow{2}{*}{ No. } & \multirow{2}{*}{ Kegiatan } & \multicolumn{2}{|c|}{ Patuh } & \multicolumn{2}{|c|}{ Tidak Patuh } & \multicolumn{2}{|c|}{ Jumlah } \\
\hline & & $n$ & $\%$ & $n$ & $\%$ & $n$ & $\%$ \\
\hline 1. & $\begin{array}{l}\text { Perawat mengkonfirmasi pasien } \\
\text { (identitas dan gelang pasien, lokasi } \\
\text { operasi, prosedur, inform consent } \\
\text { tindakan) }\end{array}$ & 122 & 89,1 & 15 & 10,9 & 137 & 100 \\
\hline 2. & $\begin{array}{l}\text { Perawat mengkonfirmasi lokasi } \\
\text { operasi sudah diberi tanda }\end{array}$ & 131 & 95,6 & 6 & 4,4 & 137 & 100 \\
\hline 3. & $\begin{array}{l}\text { Mesin dan obat anestesi sudah dicek } \\
\text { lengkap }\end{array}$ & 133 & 97,1 & 4 & 3,9 & 137 & 100 \\
\hline 4. & $\begin{array}{l}\text { Pulse oximeter sudah terpasang dan } \\
\text { berfungsi }\end{array}$ & 137 & 100 & 0 & 0 & 137 & 100 \\
\hline 5. & $\begin{array}{l}\text { Ahli anestesi mengkonfirmasi apakah } \\
\text { pasien mempunyai riwayat alergi }\end{array}$ & 111 & 81 & 26 & 19 & 137 & 100 \\
\hline 6. & $\begin{array}{l}\text { Ahli anestesi mengkonfirmasi apakah } \\
\text { pasien ada kesulitan bernafas/ resiko } \\
\text { aspirasi dan penggunaan alat bantu } \\
\text { nafas }\end{array}$ & 126 & 92 & 11 & 8 & 137 & 100 \\
\hline 7. & $\begin{array}{l}\text { Ahli anestesi meng konfirmasi risiko } \\
\text { kehilangan darah }\end{array}$ & 127 & 92,7 & 10 & 7,3 & 137 & 100 \\
\hline 8. & $\begin{array}{l}\text { Ahli anestesi mengkonfirmasi akses } \\
\text { iv/ rencana terapi cairan }\end{array}$ & 135 & 98,5 & 2 & 1,5 & 137 & 100 \\
\hline
\end{tabular}

Pada fase sign in ini item 5 ( ahli anestesi mengkonfirmasi apakah pasien mempunyai riwayat alergi) merupakan item yang paling sering tidak dilakukan dan item 4 (pulse oximeter sudah terpasang dan berfungsi) merupakan item yang bisa dipatuhi pada semua pasien, dimana keduanya merupakan tugas dan tanggungjawab dari tim anestesi. Hampir semua item di fase ini belum dipatuhi kecuali item 4. 
Tabel 5. Distribusi frekuensi kepatuhan tim bedah yang melaksanakan surgical safety checklist fase time out pada operasi seksio sesarea di RSUD Barru

\begin{tabular}{|c|c|c|c|c|c|c|c|}
\hline \multirow{2}{*}{ No. } & \multirow{2}{*}{ Kegiatan } & \multicolumn{2}{|c|}{ Patuh } & \multicolumn{2}{|c|}{ Tidak Patuh } & \multicolumn{2}{|c|}{ Jumlah } \\
\hline & & $\mathrm{n}$ & $\%$ & $n$ & $\%$ & $\mathbf{n}$ & $\%$ \\
\hline 1. & $\begin{array}{l}\text { Tim bedah memperkenalkan nama dan } \\
\text { peran masing-masing }\end{array}$ & 104 & 75,9 & 33 & 24,1 & 137 & 100 \\
\hline 2. & $\begin{array}{l}\text { Tim bedah secara verbal konfirmasi nama } \\
\text { pasien, prosedur, lokasi insisi }\end{array}$ & 127 & 92,7 & 10 & 7,3 & 137 & 100 \\
\hline 3. & $\begin{array}{l}\text { Ahli anestesi mengkonfirmasi pemberian } \\
\text { antibiotik profilaksis }\end{array}$ & 112 & 81,8 & 25 & 18,2 & 137 & 100 \\
\hline 4. & $\begin{array}{l}\text { Antisipasi keadaan kritis (antisipasi } \\
\text { kehilangan darah, peralatan sudah steril) }\end{array}$ & 134 & 97,8 & 3 & 2,2 & 137 & 100 \\
\hline 5. & $\begin{array}{l}\text { Apakah alat operasi dan resusitasi bayi } \\
\text { sudah siap dan tidak ada masalah }\end{array}$ & 118 & 86,1 & 19 & 13,9 & 137 & 100 \\
\hline
\end{tabular}

Pada fase time out ini item 1 (tim bedah memperkenalkan nama dan peran masing-masing) dan item 3 (ahli anestesi mengkonfirmasi pemberian antibiotik profilaksis) merupakan item yang paling sering tidak dipatuhi. Item 1 merupakan tugas dan tanggungjawab tim, sedang item 3 merupakan tugas dari dokter ahli anestesi. Yang juga perlu mendapat perhatian adalah item 5 (apakah alat operasi dan resusitasi bayi sudah siap dan tidak ada masalah) yang merupakan tanggungjawab perawat OK dan tim resusitasi neonatus. Semua item pada fase ini tidak ada yang dipatuhi sepenuhnya.

Tabel 6. Distribusi frekuensi kepatuhan tim bedah yang melaksanakan surgical safety checklist fase sign out pada operasi seksio sesarea di RSUD Barru.

\begin{tabular}{|c|c|c|c|c|c|c|c|}
\hline \multirow{2}{*}{ No. } & \multirow{2}{*}{ Kegiatan } & \multicolumn{2}{|c|}{ Patuh } & \multicolumn{2}{|c|}{ Tidak Patuh } & \multicolumn{2}{|c|}{ Jumlah } \\
\hline & & $\mathbf{n}$ & $\%$ & $\mathbf{n}$ & $\%$ & $\mathbf{n}$ & $\%$ \\
\hline \multirow[t]{5}{*}{1.} & Perawat mengkonfirmasi : & & & & & & \\
\hline & Prosedur operasi sudah dicatat & 133 & 97,1 & 4 & 2,9 & 137 & 100 \\
\hline & Instrumen telah dihitung dengan benar & 121 & 88.3 & 16 & 11,7 & 137 & 100 \\
\hline & Spesimen telah diberi label & 137 & 100 & 0 & 0 & 137 & 100 \\
\hline & Adakah masalah peralatan selama operasi & 115 & 83,9 & 22 & 16,1 & 137 & 100 \\
\hline 2. & $\begin{array}{l}\text { Tim Bedah mereview apakah ada masalah yang } \\
\text { harus diperhatikan dan manajemen selanjutnya }\end{array}$ & 137 & 100 & 0 & 0 & 137 & 100 \\
\hline
\end{tabular}

Pada fase sign out ini item $1 \mathrm{~b}$ dan $\mathrm{d}$ (perawat mengkonfirmasi bahwa instrumen telah dihitung dengan benar dan adakah masalah peralatan selama operasi) yang merupakan tugas dari perawat
OK merupakan item yang paling tidak dipatuhi, sedang item 2 (tim bedah mereview apakah ada masalah yang harus diperhatikan dan manajemen selanjutnya) dapat dipatuhi pada semua pasien. 
Tabel 7. Gambaran kepatuhan tim bedah pada fase sign in, time out, dan sign out

\begin{tabular}{llcccccc}
\hline \multirow{2}{*}{ No. SSC } & \multicolumn{2}{c}{ Patuh } & \multicolumn{2}{c}{ Tidak Patuh } & \multicolumn{2}{c}{ Jumlah } \\
\cline { 3 - 8 } & & $\mathbf{n}$ & $\%$ & $\mathbf{n}$ & $\%$ & $\mathbf{n}$ & $\%$ \\
\hline & Fase & & & & & & \\
1. & Sign In & 94 & 68,6 & 43 & 31,4 & 137 & 100 \\
2. & Time Out & 91 & 66,4 & 46 & 33,6 & 137 & 100 \\
3. & Sign Out & 104 & 75,9 & 33 & 24,1 & 137 & 100 \\
& Tim Bedah & & & & & & \\
1. & Dokter Obgin & 94 & 68,6 & 43 & 31,4 & 137 & 100 \\
2. & Tim Anestesi & 91 & 66,4 & 46 & 33,6 & 137 & 100 \\
3. & Perawat OK & 91 & 66,4 & 46 & 33,6 & 137 & 100 \\
4. & Tim Resusitasi Neonatus & 120 & 87,6 & 17 & 12,4 & 137 & 100 \\
\hline
\end{tabular}

Pada tabel 7 menunjukkan fase terbanyak tidak dipatuhi dan profesi yang paling banyak tidak patuh terhadap penerapan SSC ini. Pada tabel 8 menunjukkan berapa banyak item yang tidak dipatuhi. Pada penelitian ini tim bedah dianggap tidak patuh apabila sudah ada 1 item yang tidak dilakukan pada lembar SSC ini. Setiap item dari ceklis bisa merupakan tanggung jawab masingmasing profesi, tapi juga bisa menjadi tanggung jawab bersama.

Fase time out $(33,6 \%)$ merupakan fase yang paling banyak tidak dipatuhi lalu fase sign in $(31,4 \%)$, kemudian fase sign out $(24,1 \%)$.

Semua tim operasi (perawat OK, dokter ahli, tim anestesi, maupun tim resusitasi bayi) belum patuh sepenuhnya dalam penerapan SSC, dimana perawat OK dan tim Anestesi merupakan yang terbanyak tidak patuh dalam penerapan SSC ini yaitu 46 pasien (33,6\%).

Beberapa item dari ceklis justru tidak dipatuhi oleh tim bedah seperti yang tergambar pada tabel 8 dan hanya pada 7 pasien dimana 1 item yang tidak dipatuhi.
Tabel 8. Distribusi berdasarkan jumlah item yang tidak dipatuhi pada semua fase pada SSC

\begin{tabular}{ccc}
\hline \multirow{2}{*}{ Jumlah Item } & \multicolumn{2}{c}{ Tidak Patuh } \\
\cline { 2 - 3 } & $\mathbf{n}$ & $\%$ \\
\hline 6 & 7 & 14,3 \\
5 & 12 & 24,5 \\
4 & 16 & 32,7 \\
3 & 5 & 10,2 \\
2 & 2 & 4,0 \\
1 & 7 & 14,3 \\
Total & 49 & 100 \\
\hline
\end{tabular}

Pada tabel 8 menunjukkandistribusi jumlah item yang tidak dipatuhi oleh tim pada semua fase .

\section{Hubungan kepatuhan tim bedah dengan ILO dan lama rawat inap}

Tabel 9 dan tabel 10 menunjukkan ada tidaknya hubungan antara kepatuhan tim bedah dengan ILO dan lama rawat inap. 
Tabel 9. Hubungan Kepatuhan tim bedah terhadap SSC dengan infeksi luka operasi

\begin{tabular}{|c|c|c|c|c|c|}
\hline \multirow[t]{2}{*}{ SSC } & \multicolumn{2}{|c|}{ Infeksi luka operasi } & \multirow[t]{2}{*}{ Persen } & \multirow[t]{2}{*}{$\mathrm{RR}(95 \mathrm{Cl})$} & \multirow[t]{2}{*}{$\mathbf{p}$} \\
\hline & $\mathrm{Ya}$ & Tidak & & & \\
\hline Tidak Patuh & 8 & 41 & 16,33 & $2,39(0,88-6,5)$ & 0,078 \\
\hline Patuh & 6 & 82 & 6,82 & 1 & \\
\hline
\end{tabular}

Dengan uji Pearson Chi Square didapatkan $p>0,05$,

Hasil ini menunjukkan bahwa tidak terdapat hubungan bermakna antara kepatuhan penerapan SSC dengan tidak terjadinya infeksi pasca seksio sesarea.

Tabel 10. Hubungan Kepatuhan tim bedah terhadap SSC dengan lamanya rawat inap

\begin{tabular}{|c|c|c|c|c|c|}
\hline \multirow{2}{*}{ SSC } & \multicolumn{2}{|c|}{ Lama rawat inap } & \multirow{2}{*}{ Persen } & \multirow{2}{*}{ RR (95 Cl) } & \multirow{2}{*}{$\mathbf{p}$} \\
\hline & $>4$ hari & $\leq 4$ hari & & & \\
\hline Tidak Patuh & 28 & 21 & 57,14 & $1,73(1,18-2,55)$ & \\
\hline Patuh & 29 & 59 & 32,95 & 1 & 0,006 \\
\hline
\end{tabular}

Dengan uji Pearson Chi Square didapatkan $p<0,05$,

Hasil ini menunjukkan bahwa terdapat hubungan yang bermakna antara kepatuhan penerapan SSC dengan lamanya hari rawat inap di RS pada pasien seksio sesarea.

\section{Hubungan variabel luar dengan ILO dan lama rawat inap}

Tabel 11 dan tabel 12 menunjukkan bagaimana hubungan antara variabel luar yaitu umur, paritas, diagnosis, dan kedaruratan terhadap ILO dan lamanya rawat inap pasien seksio sesarea .

Tabel 11. Hubungan variabel luar dan infeksi luka operasi

\begin{tabular}{|c|c|c|c|c|c|}
\hline \multirow{2}{*}{ Variabel Luar } & \multicolumn{2}{|c|}{ Infeksi luka operasi } & \multirow{2}{*}{ Persen } & \multirow{2}{*}{ RR (95\%Cl) } & \multirow{2}{*}{$\mathbf{P}$} \\
\hline & ya & tidak & & & \\
\hline \multicolumn{6}{|l|}{ Umur } \\
\hline$<20$ dan $>35$ & 3 & 29 & 9,38 & $0,89(0,27-3,01)$ & 0,86 \\
\hline $20-35$ & 11 & 94 & 10,48 & 1 & \\
\hline \multicolumn{6}{|l|}{ Paritas } \\
\hline Primi & 6 & 54 & 10,00 & $0,96(0,35-2,63)$ & 0,94 \\
\hline Multi & 8 & 69 & 10,39 & 1 & \\
\hline \multicolumn{6}{|l|}{ Diagnosis } \\
\hline KPD & 5 & 34 & 12,82 & $1,40(0,50-3,90)$ & 0,53 \\
\hline Bukan KPD & 9 & 89 & 9,18 & 1 & \\
\hline \multicolumn{6}{|l|}{ Kedaruratan } \\
\hline Emergensi & 12 & 94 & 11,32 & $1,76(0,42-7,42)$ & 0,43 \\
\hline Elektif & 2 & 29 & 6,45 & 1 & \\
\hline
\end{tabular}


Pada tabel 11 tidak ditemukan hubungan yang bermakna antara umur, paritas, diagnosis, dan kedaruratan dengan infeksi luka operasi

Tabel 12. Hubungan variabel luar dan lama rawat inap

\begin{tabular}{|c|c|c|c|c|c|}
\hline \multirow{2}{*}{ Variabel Luar } & \multicolumn{2}{|c|}{ Lama rawat inap } & \multirow{2}{*}{ Persen } & \multirow{2}{*}{ RR (95\%CI) } & \multirow{2}{*}{$\mathbf{P}$} \\
\hline & $>4$ hari & $\leq 4$ hari & & & \\
\hline \multicolumn{6}{|l|}{ Umur } \\
\hline$<20$ dan $>35$ & 11 & 21 & 34,38 & $0,79(0,46-1,331)$ & 0,34 \\
\hline $20-35$ & 46 & 59 & 43,81 & 1 & \\
\hline \multicolumn{6}{|l|}{ Paritas } \\
\hline Primi & 18 & 42 & 30.00 & $0,59(0,38-0,92)$ & 0,02 \\
\hline Multi & 39 & 38 & 50,65 & 1 & \\
\hline \multicolumn{6}{|l|}{ Diagnosis } \\
\hline KPD & 14 & 25 & 35.90 & $0,82(0,51-1,32)$ & 0,39 \\
\hline Bukan KPD & 43 & 55 & 43,88 & 1 & \\
\hline \multicolumn{6}{|l|}{ Kedaruratan } \\
\hline Emergensi & 46 & 60 & 43,40 & $1,22(0,73-2,06)$ & 0,43 \\
\hline Elektif & 11 & 20 & 35,48 & 1 & \\
\hline
\end{tabular}

Pada tabel 12 terlihat bahwa tidak ditemukan hubungan yang bermakna antara umur, diagnosis, dan kedaruratan dengan lamanya rawat inap $(p>0,05)$, tetapi pada paritas didapatkan hubungan yang bermakna dengan lamanya hari rawat $(p<$ $0,05)$.

Melihat data karakteristik responden dan luaran maternal pada tabel 1 dan jika dibandingkan dengan data dari rekam medik pasien seksio sesarea pada tahun sebelumnya (Desember 2015 - April 2016) ada beberapa catatan yaitu :

a. Jumlah ibu dengan umur risiko tinggi $\quad<20$ thn dan $>35$ thn) menurun dibanding tahun sebelumnya $(39,1 \%$ turun $23,4 \%)$

b. Ibu primigravida meningkat ( $40,6 \%$ naik $43,8 \%)$

c. Diagnosis terbanyak KPD

d. ILO menurun dibanding tahun sebelumnya (21,8 \% turun $10,2 \%)$

d. Rawat inap $>4$ hari menurun dibanding tahun sebelumnya ( $60.1 \%$ turun $41,6 \%$ )

e. Tidak ada kematian maternal pasien pasca seksio sesarea

Pada penelitian ini ditemukan 14 pasien $(10,2 \%)$ yang mengalami ILO. Angka ini sudah menunjukkan penurunan dibanding tahun sebelumya yaitu 29 pasien (21,8\%). Jadi ada penurunan ILO hingga > $50 \%$ jika dibanding ILO tahun sebelumnya.

Begitupun dengan lama rawat inap, dimana ada 57 pasien $(41,6 \%)$ yang dirawat $>4$ hari. Terdapat penurunan jumlah pasien yang dirawat $>4$ hari dibanding tahun sebelumnya sebanyak 80 pasien $(60,1 \%)$. Jadi ada penurunan lama rawat inap $>4$ hari hingga hampir $20 \%$ dibanding tahun sebelumnya. Diagnosis terbanyak yang mengalami ILO dan hari rawat $>4$ hari adalah KPD dan malposisi.

Penelitian oleh Ng W terhadap 7985 ibu yang dilakukan seksio sesarea yang mendapatkan penurunan angka ILO (8,2\% menjadi 4,1\%) pada penggunaan penggunaan SSC yang benar, penggunaan antibiotik dengan timing yang tepat dan edukasi prenatal. Bagaimanapun juga penurunan angka ILO ikut mempengaruhi penurunan lamanya rawat inap pasien.?

Dalam penelitian ini dilakukan juga uji pengetahuantentangSSCkepadaseluruhyangterlibat di kamar operasi (dokter ahli, perawat anestesi, dan perawat OK). Pengetahuan dan keterampilan tentang keselamatan memiliki hubungan yang kuat dengan kepatuhan. ${ }^{8}$ Pengetahuan yang kurang bisa menyebabkan kepatuhan penerapan SSC rendah dan kelengkapan pengisian juga rendah. Hasil penelitian 
untuk pengetahuan tentang SSC menyatakan bahwa $61 \%$ petugas kamar bedah memperoleh nilai kurang dari 60 , pengetahuan yang kurang ini menyebabkan kepatuhan penerapan SSC rendah dan kelengkapan pengisian juga rendah. ${ }^{9}$ Penelitian oleh Setiawati juga mendapatkan hubungan antara pengetahuan tim bedah dan kepatuhan penerapan SSC pada pasien operasi bedah mayor di IBS RSUD Dr.Soedirman Kebumen. Hasil uji pengetahuan didapatkan dokter ahli sangat baik, perawat anestesi cukup dan petugas OK masih kurang. Oleh karena itu sebelum pelaksanaan penelitian ini, maka dianggap perlu untuk melakukan sosialisasi kembali tentang SSC kepada semua staf khususnya kepada seluruh perawat OK dengan menjelaskan setiap bagian di dalam ceklis ini sehingga mereka bisa lebih memahami peran dan tanggung jawab masingmasing di tiap bagian ceklis tersebut. Meskipun demikian ternyata dalam penerapannya tidaklah mudah, karena masih sering terdapat bagian-bagian yang terlupakan untuk dilaksanakan. ${ }^{10}$

Pada fase sign in item 5 (ahli anestesi mengkonfirmasi apakah pasien mempunyai riwayat alergi) merupakan item yang paling sering tidak dilakukan, sedangkan item 4 (pulse oximeter sudah terpasang dan berfungsi) merupakan item yang paling dipatuhi, dimana keduanya merupakan tugas dan tanggungjawab dari tim anestesi. Hampir semua item di fase ini belum dipatuhi kecuali item 4. Sama dengan Penelitian oleh Hasri yang melaporkan bahwa pelaksanaan SSC pada fase Sign in yang dilakukan secara konsisten (100\%) adalah pengecekan kelengkapan anestesi dan fungsi pulse oksimeter. ${ }^{11}$

Saputra dkk menyampaikan hasil penelitiannya bahwa observasi pada siklus pertama hingga ketiga menunjukkan bahwa seluruh perawat anestesi tidak patuh (100\%) dalam mengisi surgical safety checklist: sign In. Hasil dari respon setiap siklus dan wawancara terstruktur dengan dokter anestesi menunjukkan bahwa perawat masih bingung cara menggunakan ceklis, ceklis belum menjadi kebutuhan, budaya patient safety masih minim, kualitas SDM kurang, belum adanya mekanisme pengawasan dan kurangnya sosialisasi surgical safety checklist ini yang mempengaruhi ketidakpatuhan perawat untuk mengisi sign in. ${ }^{12}$

Pada fase time out item 1 (tim bedah memperkenalkan nama dan peran masing-masing) merupakan item yang paling tidak dipatuhi oleh tim bedah. Beberapa faktor yang mempengaruhi hal ini antara lain: masih adanya persepsi bahwa memperkenalkan diri bukan hal penting dalam tahapan operasi, memperkenalkan diri terkadang tidak dilakukan lagi jika tim yang sama terlibat kembali pada operasi berikutnya, merasa sudah saling kenal dengan semua tim bedah sehingga tidak perlu lagi untuk memperkenalkan diri. Selain item 1 , item 3 (pemberian antibiotik profilaksis) merupakan item yang sering juga tidak dipatuhi. Pemberian antibiotik profilaksis yang direkomendasikan sesuai SPO di bagian kebidanan RSUD Barru adalah ceftriaxone $1 \mathrm{gr}$ diberikan dalam 1 jam hingga insisi kulit. Antibiotik profilaksis ini sangat penting untuk mengurangi terjadinya infeksi luka operasi. Yang juga perlu mendapat perhatian adalah item 5 (apakah alat operasi dan alat resusitasi bayi sudah siap dan tidak ada masalah) yang merupakan bagian dari tanggungjawab perawat OK dan tim resusitasi neonates, karena masih tidak dipatuhi pada 19 pasien. Semua item pada fase ini tidak satupun yang bisa dipatuhi sepenuhnya.

Item 1 (Safety briefing) pada time out cukup penting karena memungkinkan anggota tim saling memperkenalkan diri dan perannya dalam tim, kondisi pasien, potensi penyulit yang mungkin muncul, kebutuhan peralatan khusus, posisi pasien, dll. Tanpa perkenalan yang cukup, tim operasi bisa jadi bekerja tanpa saling mengetahui nama masingmasing. Akibatnya, akan sulit bagi anggota tim untuk bertanya, mengingatkan atau memberitahu jika ada masalah yang terjadi. Meskipun masih banyak dokter dan perawat yang masih menganggap proses ini tidak penting, tetapi pada kenyataannya briefing berhasil meningkatkan level komunikasi dalam tim, mengurangi terjadinya error dan keterlambatan yang tidak diharapkan. ${ }^{13}$

Pada fase sign out ini item $1 \mathrm{~b}$ dan $\mathrm{d}$ (perawat mengkonfirmasi bahwa instrumen telah dihitung dengan benar dan adakah masalah peralatan selama operasi) yang merupakan tugas dari perawat OK merupakan item yang paling tidak dipatuhi, sedang item 2 (tim Bedah mereview apakah ada masalah yang harus diperhatikan dan manajemen selanjutnya) bisa dipatuhi pada semua pasien. Menghitung instrumen, kasa, dan bahan habis pakai lainnya sangatlah penting untuk mencegah tertinggalnya alat dan bahan tersebut di dalam 
abdomen, sehingga menghindarkan kita dari tuntutan malpraktik.

Semua tim bedah (perawat OK, dokter ahli, tim anestesi, maupun tim resusitasi bayi) belum patuh sepenuhnya dalam penerapan SSC dan dalam penelitian ini ketidakpatuhan tim pada SSC justru banyak dengan tidak mematuhi beberapa item (terbanyak 4 dan 5 item). Cabana et al menganalisis 76 artikel tentang hambatan kepatuhan dokter terhadap suatu pedoman praktis klinis. Hambatan dibedakan menjadi tiga yaitu pengetahuan dokter (kurangnya kesadaran dan kurangnya pemahaman), sikap (kurangnya kesepakatan, kurangnya efektivitas diri, kurangnya hasil yang diharapkan) dan perilaku (hambatan eksternal). Pengetahuan dan sikap dokter merupakan hambatan penerapan kepatuhan yang paling sering.$^{14}$

Pada penelitian yang dilakukan oleh Sandrawati dkk., menemukan beberapa faktor hambatan dalam penerapan SSC antara lain: ${ }^{9}$

1. Kurangnya tenaga perawat

2. Belum paham tentang pelaksanaan SSC

3. Petugas belum terbiasa ( sering lupa)

4. Dokter terburu-buru

5. Kurang kesadaran pentingnya SSC

6. Hambatan komunikasi antara dokter dan perawat

Rekomendasi yang dianjurkan agar kepatuhan terhadap SSC bisa berjalan dengan baik antara lain:

1. Membuat kebijakan tentang sasaran keselamatan pasien dan penerapan SSC secara tertulis

2. Sosialisasi SPO untuk para dokter, seperti pertemuan kelompok Staf Medis Bedah dan Anestesi, Siang Klinik atau pertemuan khusus dokter bedah dan anestesi

3. Sosialisasi untuk perawat tentang SSC dan SPO yang berkaitan dengan pelaksanaan SSC

4. Pelatihan penerapan SSC untuk perawat kamar bedah agar mengetahui dan memahami tahapan yang harus dilakukan sehingga pelaksanaan SSC dapat berjalan dengan baik. Pembuatan video pelaksanaan SSC merupakan alat bantu untuk pelatihan. Dalam pelatihan perlu ada role play secara bergantian agar para perawat semakin memahami pelaksanaan SSC.

5. Empower nurse (pemberdayaan perawat) dan meningkatkan peran advokasi perawat di ruangan dan di kamar bedah. Perawat sebagai "mitra kerja" dokter dapat mengingatkan bila dokter belum visite, memberi tanda daerah operasi, melakukan asesmen preoperasi, memberikan informed consent, dan sebagainya.

6. Penyediaan fasilitas dan membuat reminder:

a. SSC berupa poster atau lembar balik yang dipasang di tempat yang strategis di kamar bedah untuk mengingatkan perawat dan dokter, seperti di pintu masuk kamar bedah dan nurse station.

b. Pemberian tanda berupa poster yang dipasang di nurse station ruangan agar mengingatkan perawat dan dokter yang visite.

7. Membudayakan pelaporan insiden keselamatan pasien

8. Evaluasi pelaksanaan SSC

Evaluasi dilakukan untuk melihat pencapaian indikator keberhasilan dan mengetahui hambatan yang ada dalam pelaksanaan SSC. Dari hasil evaluasi dibuat suatu tindak lanjut perbaikan.

Beberapa penelitian menunjukan adanya hubungan antara kepatuhan pada SSC dengan morbiditas dan mortalitas pada ibu yang melahirkan dengan seksio sesarea. Untuk itu pada penelitian ini peneliti mencoba melihat apakah ada hubungan antara kepatuhan tim bedah dalam penerapan SSC dengan infeksi luka dan lamanya hari rawat inap.

Hasil yang didapatkan pada penelitian ini menunjukkan bahwa tidak terdapat hubungan bermakna antara kepatuhan penerapan SSC dengan tidak terjadinya infeksi pasca seksio sesarea dengan nilai $p=0.078$ ( $p>0,05)$. Meskipun demikian dalam beberapa penelitian justru terdapat hubungan yang signifikan antara kepatuhan penerapan SSC dengan infeksi luka operasi .

Haynes et al., melaporkan hasil penelitian sebelum dan setelah implementasi dari SSC WHO. Pilot Study yang dikuti 8 Rumah Sakit di dunia dengan keadaan sosial ekonomi rendah, menengah dan tinggi, hasilnya 3733 pasien sebelum implementasi dan 3955 setelah implementasi checklist tersebut. Hasil penelitian menunjukkan angka komplikasi menurun dari $11 \%$ menjadi $7 \%(p<0,001)$. Angka kematian juga menurun dari $1,5 \%$ menjadi $0,8 \%$ $(p=0,003)$. Komplikasi infeksi luka operasi (ILO) menurun dari $6,2 \%$ menjadi $3,4 \% \quad(p<0,001)$, 
pembedahan ulang tanpa terencana menurun dari $2,4 \%$ menjadi $1,8 \%(p=0,047){ }^{1}$

Hasil penelitian serupa juga ditemukan oleh Vries et al., pada 6 Rumah Sakit di Belanda, sebelum dan setelah implementasi SSC. Hasil studi ini angka komplikasi menurun dari $27,3 \%$ menjadi $16,7 \%(p<0,001)$. Kematian pasien menurun dari $1,5 \%$ menjadi $0,8 \%(p=0,003)$. Komplikasi respirasi menurun dari $3,3 \%$ menjadi $2,1 \% \quad(p=0,004)$, komplikasi abdominal menurun dari 3,5\% menjadi $2,4 \%$, infeksi turun dari $3,8 \%$ menjadi $2,7 \%$ $(p=0,006)$, wound complication menurun dari $1,5 \%$ menjadi $0,8 \% \quad(p=0,008)$, perdarahan menurun dari $2,0 \%$ menjadi $0,9 \% \quad(p=0,001)$, kecacatan sementara yang membutuhkan pembedahan ulang menurun dari $3,7 \%$ menjadi $2,5 \%(p=0,005)$. Berdasarkan penelitian tersebut menunjukkan bahwa implementasi ceklis akan menurunkan angka kematian dan komplikasi pada pembedahan. ${ }^{2}$

Begitu juga dengan studi prospektif sebelum dan setelah intervensi SSC pada pasien dewasa dengan pembedahan emergency non kardiak, pada 8 rumah sakit di dunia, dengan 842 pasien sebelum intervensi dan 908 pasien setelah intervensi. Angka komplikasi menurun dari $18,4 \%$ menjadi $11,7 \%$ $(p=0,0001)$ setelah intervensi SSC. Angka kematian menurun dari $3,7 \%$ menjadi $1,4 \%(p=0,0067)$. Angka infeksi luka operasi menurun dari $11,2 \%$ menjadi $6,6 \%(p=0,0008)$. Estimasi kehilangan darah lebih dari $500 \mathrm{ml}$ menurun dari $20,2 \%$ menjadi $13,2 \%$ $(p<0,0001) .^{5}$

Penelitian-penelitian diatas menunjukkan besarnya manfaat penerapan SSC pada pasien yang menjalani pembedahan dalam menurunkan komplikasi operasi terutama dalam mengurangi kejadian infeksi luka operasi (ILO). Dan meskipun dalam penelitian ini tidak ditemukan hubungan yang bermakna antara kepatuhan dan ketidakpatuhan dalam penerapan SSC dengan kejadian ILO, tapi terdapat penurunan ILO yang cukup bermakna bila dibanding dengan ILO pada tahun sebelumnya dimana SSC belum tersosialisasi dengan baik $(21,8 \%$ turun menjadi 10,2\%). Hasil penelitian ini juga menunjukkan bahwa ketidakpatuhan terhadap penerapan SSC 2,39 kali kemungkinan bisa terjadi infeksi luka operasi .

Sedangkan untuk lama hari rawat, hasil penelitian ini menunjukkan adanya hubungan yang bermakna antara kepatuhan penerapan SSC dengan lamanya hari rawat inap pasien seksio sesarea, dimana nilai $p=0,006(p<0,05)$.

Bagaimanapun jika terjadi komplikasi pasca operasi akan berpotensi menyebabkan perawatan pada pasien menjadi lebih lama. Dengan penerapan SSC dengan benar diharapkan akan dapat mengurangi komplikasi yang bisa terjadi pasca operasi sehingga pasien tidak memerlukan perawatan di RS yang lebih lama. Hal ini tidak saja efektif dalam meningkatkan mutu pelayanan tapi juga efektif dalam menekan biaya RS. Infeksi luka operasi (ILO) merupakan salah satu komplikasi pembedahan terbanyak. Hasil studi di Inggris menunjukkan bahwa ILO memperpanjang rata-rata lama rawat inap menjadi 6,5 hari. Oleh karena itu ILO menjadi pengukuran penting pada tindakan pembedahan. ${ }^{15}$ Penelitian Yuniar dkk mendapatkan komplikasi pasca operasi pada 32 subyek (12,5\%) dan komplikasi terbanyak adalah infeksi luka operasi yaitu 27 subyek (10,5\%). Hasil analisis multivariat pada faktor pembedahan didapatkan faktor yang berhubungan secara bermakna untuk terjadinya luaran klinis yaitu lamanya dirawat di rumah sakit ( $R R=3,98 ; 95 \% C l: 1,78-8,89585) \quad(p=0,001)$. Pada analisis multivariat pada SSC, subyek yang tidak mendapatkan antibiotik profilaksis sebelum pembedahan secara bermakna memiliki risiko 2,59 kali untuk terjadinya ILO dibandingkan subyek yang mendapat antibiotik profilaksis ( $R R=2,59 ; 95 \% \mathrm{Cl}$ : $1,06-6,28) \quad(p=0,036) \cdot{ }^{16}$ Dari penelitian oleh Rivai dkk mendapatkan waktu pemberian antibiotik, lama rawat prabedah dan lama rawat pascabedah berhubungan signifikan dengan kejadian ILO (nilai $p \leq 0,05)$. Hasil analisis multivariat menunjukkan bahwa lama rawat pascabedah merupakan faktor risiko yang paling dominan berpengaruh terhadap kejadian ILO (OR = 1,21; 95\% Cl = 1,04_ 1,40), waktu pemberian antibiotik profilaksis $(\mathrm{OR}=1,16 ; 95 \% \mathrm{Cl}$ $\left.=1,10 \_1,24\right)$, dan lama rawat prabedah $(O R=1,12$; $\left.95 \% \mathrm{Cl}=1,01 \_1,24\right)$ dengan nilai $p<0,05 .{ }^{17}$

Penelitian tentang analisis lama hari rawat pasien yang menjalani pembedahan di RSUD Sanglah Denpasar 2012 yang dilakukan oleh wartawan IW didapatkan hubungan yang bermakna antara lamanya hari rawat dengan faktor-faktor sbb: diagnosis penyakit, komplikasi operasi, jenis operasi, tehnik operasi, dan pelaksana operasi.

Dalam penelitian ini selain kita dapatkan hubungan yang bermakna antara kepatuhan pene- 
rapan SSC dengan lamanya rawat inap juga terdapat penurunan yang signifikan $(18,5 \%)$ pada lama rawat inap $>4$ hari pada pasien seksio sesarea dibanding tahun sebelumnya (60,1 \% menjadi $41,6 \%)$.

Uji komparibilitas antar kelompok pada penelitian ini tidak menunjukkan perbedaan yang bermakna antara kepatuhan dengan umur, paritas, KPD, dan kedaruratan. Hasil uji statistik untuk melihat hubungan variabel luar dengan ILO dan lama rawat inap tidak ditemukan hubungan yang bermakna pada hampir semua variabel, kecuali hubungan antara paritas dan lama rawat inap dengan nilai $p=$ $0,02(p<0,05)$.

Uji multivariat dilakukan pada penelitian ini untuk melihat hubungan kepatuhan bersama variabel luar dengan ILO dan lama rawat inap. Hasil yang didapat tidak menunjukkan hubungan bermakna hampir semua variabel dengan ILO dan lama rawat inap, kecuali kepatuhan dan lama rawat inap dengan nilai $p=0,01(p<0,05)$. Kepatuhan dan paritas adalah dua varibel yang paling berpangaruh baik pada kejadian ILO $(\mathrm{OR}=2,56$ dan 1,26$)$ maupun pada lama rawat inap $(\mathrm{OR}=2,53$ dan 3,00$)$.

Pada penelitian ini dilakukan juga analisis hubungan antara infeksi luka operasi dengan lama rawat inap, namun tidak ditemukan adanya hubungan yang bermakna. Hasil ini kemungkinan dipengaruhi oleh karena sebagian dari kasus infeksi luka operasi tersebut justru ditemukan saat pasien melakukan kunjungan ulang di poliklinik.

Agar penggunaan surgery safety checlist bisa efektif dalam menurunkan angka komplikasi operasi dan kematian, maka diharapkan semua personil tim bedah bisa patuh dalam penggunaan lembar ceklis ini. Kepatuhan ini tentu banyak dipengaruhi oleh sikap, pengetahuan, dan perilaku oleh anggota tim (dokter bedah, dokter anestesi, penata anestesi, perawat kamar operasi, dan tim resusitasi bayi) yang terlibat didalamnya. Diperlukan komitmen bersama sehingga penerapan SSC ini bisa berjalan dengan baik dan benar.

Pada penelitian ini menunjukkan bahwa SSC ternyata belum bisa diterapkan dengan baik pada semua pasien, karena masih ada bagian-bagian tertentu yang tidak dipatuhi. Dari 137 pasien dalam penelitian terdapat 49 pasien (36\%) dimana langkahlangkah pada SSC tidak dilaksanakan sepenuhnya. Salah satu kendalanya adalah karena masih kurang dipahaminya fungsi dan peran masing-masing di setiap fase dari ceklis ini. Untuk itu diperlukan sosialisasi kembali agar memastikan semua anggota tim tidak mengalami kesulitan dalam penerapan SSC. Salah satu upaya yang bisa dilakukan di RSUD Barru nantinya adalah dengan membuat panduan SSC di RS dalam bentuk lembar implementasi manual sehingga seluruh anggota tim memahami tugas dan perannya masing-masing.

\section{KESIMPULAN DAN SARAN}

Diagnosis terbanyak dalam penelitian ini adalah ketuban pecah dini. Masih kurang patuhnya tim bedah dalam penerapan SSC, dimana masih ada 49 pasien (36\%) yang belum diterapkan secara sepenuhnya. Meskipun tidak ditemukan hubungan yang bermakna antara kejadian infeksi dan kepatuhan penerapan SSC, tapi terjadi penurunan angka ILO yang cukup signifikan dibanding tahun sebelumnya (21,8 \% turun $10,2 \%$ ). Selain ditemukan hubungan yang bermakna antara kepatuhan penerapan SSC dan lamanya hari rawat inap $(p=0,006)$, juga ada penurunan yang bermakna pada jumlah pasien yang dirawat $>4$ hari dibanding tahun sebelumnya $(60,1 \%$ turun $41,6 \%)$. Tidak ditemukan hubungan bermakna antara umur, paritas, KPD, dan kedaruratan dengan infeksi luka operasi.

\section{SARAN}

1. Pihak Manajemen RS dalam hal ini direktur RS segera membuat SPO tentang kepatuhan dalam penerapan SSC di kamar operasi .

2. Perlu sosialisasi kembali dengan memikirkan metode lain untuk meningkatkan kepatuhan petugas dalam penerapan SSC.

3. Perlunya rekomendasi ke RS tentang pentingnya penerapan SSC untuk keselamatan pasien.

4. Perlunya komitmen bersama kepada seluruh personil yang terlibat didalamnya untuk samasama mematuhi penerapan SSC ini.

5. Perlunya membuat panduan implementasi manual SSC agar seluruh anggota tim paham akan tugas dan fungsinya masing-masing.

\section{DAFTAR PUSTAKA}

1. Haynes AB, Weiser TG, Berry WR, Lipsitz SR, Breizat $A H$, Dellinger EP, Herbosa T, Joseph $S$, Kibatala PL, Lapitan MCM, Merry AF,Moorthy K, Reznick RK,Taylor B, Gawande AA, 2009. A Surgical Safety 
Checklist to Reduce Morbidity and Mortality in a Gobal Population. N Engl J Med 360(5): 491-9.

2. Vries EN, Prins HA, Crolla RMPH, Outer AJ, Ander G, Helden SH, Schlack WS, Putten MA, Gouma DJ, Dijkgraaf MGW, Smorenburg SM, Boermeester MA, 2011. Effect of a Comprehensive Surgical Safety System on Patient Outcome.N Engl J Med. 363 (20):1927-37.

3. Johnson A, Young D, Reilly J, 2006. Caesarea Section Surgical Site Infection Surveillance. J Hospt Infect 2006. 64 (1): 30.

4. Caovukian A, 2009. The Surgical Safety Checklist : A must for Hospital Performing Surgery. Information and Privacy Commisioner of Ontario

5. Weiser TG, Regenbogen SE, Thompson KD, Haynes $A B$, Lipsitz SR, Berry WR, 2009. Estimation of the Global Volume of Surgery: a Modelling Strategy Based on Available Data. Lancet. 372(9633):139-44.

6. WHO, 2009. Implementasi Manual WHO Surgical Safety Checklist

7. Ng W, Brown A, Alexander D, Ho MF, Kerr B, Amato M, Katz K, 2015. A Multifaceted Prevention Program to Reduce Infection after Caesarean Section: Intervensions Assessed Using an Intensive Postdischarge Surveillance System. Am J infect control . 43(8): 805-9.

8. Neal A, Griffin MA, Hart PM, 2000. The Impact of Organizational Climate on Safety Climate and Individual Behaviour. Safety Science. 34:99-109.

9. Sandrawati J, Supriyanto S, Nurul T, 2013. Rekomendasi untuk Meningkatkan Kepatuhan Penerapan Surgical Safety Checklist di Kamar Bedah. Fakultas Kesehatan Masyarakat Universitas Airlangga.Buletin penelitian Kesehatan Masyarakat. 17(1): 71-9.

10. Setiawati $H, 2015$. Hubungan Pengetahuan Tim Bedah terhadap Kepatuhan Penerapan Surgical
Patient Safety pada Pasien Operasi Bedah Mayor di Instalasi Bedah Sentral Rumah Sakit Umum Daerah Dr. Soedirman Kebumen. Skripsi Program S1 Keperawatan STIKES Muhammadiyah Gombong Yogyakarta

11. Hasri E, Hartriyanti Y, Haryanti F, 2012. Praktik Keselamatan Pasien di Rumah Sakit Daerah. Minat Manajemen Rumah Sakit Fakultas Kedokteran Universitas Gadjah Mada Yogyakarta. Jurnal Pelayanan Kesehatan Masyarakat,15(4): 198-202.

12. Saputra AF, Rosa EM, 2015. Pengisian Sign In dalam Meningkatkan Kepatuhan Safe Surgery di Rumah Sakit PKU Muhammaddiyah Yogyakarta II . Jurnal Manajemen RS. Vol. 4 (2).

13. Lingard L, Regehr G, Orser B, Reznick R, Baker GR, Doran D, 2008. Evaluation of a Preoperative Checklist and Team Briefing among Surgeons, Nurses, and Anesthesiologists to Reduce Failures in Communication. Arch Surg . 143(1):12-7.

14. Cabana MD, Rand CS, Powe NR, Wu AW, Wilson MH, Abboud PAC, Rubin HR, 1999 . Why don't Physicians Follow Clinical Practice Guidelines ? JAMA, 82 (15): 1458-65.

15. Scottish Intercolleageate Guidelines Network, 2008. Antibiotic Prophylaxis in Surgery, A National Clicical Guidelines. Healthcare Improvement Scotland.

16. Yuniar, Utarini A, 2013. Hubungan Praktek Keselamatan Pasien pada Tindakan Pembedahan dengan Surgery Safety Checklist WHO terhadap luaran Klinis di RSUD Muntilan Kabupaten Magelang. Perpustakaan UGM Yogyakarta.

17. Rivai F, Koentjoro T, Utarini A. Determinan Infeksi Luka Operasi Pascabedah Sesar. Bagian Manajemen Rumah Sakit FKM UGM. Jurnal Kesehatan Masyarakat Nasional. 8 (5): 235-40. 